\title{
The case of a missing person? The current $L 2$ self and the L2 Motivational Self System
}

[This is the pre-publication copy of Thorsen, C, Henry, A., \& Cliffordson, C. 'The case of a missing person? The current L2 self and the L2 Motivational Self System’. To appear in International Journal of Bilingual Education and Bilingualism]

\begin{abstract}
In Dörnyei’s (2009a) theorizing, motivation is conceptualized to be generated by discomfort associated with the learner's experience of a discrepancy between their current L2 self, and their ideal L2 self. However, in the L2 Motivational Self System, this discrepancy is not operationalized. A questionnaire containing measures of current L2 selves was administered to two cohorts of students learning English in Sweden, one in grade 7, and one in grade 9. Using structural equation modelling, results revealed that the discrepancy between the ideal L2 self and the current L2 self was greater for the grade 7 cohort. So too was the impact on a criterion variable measuring intended effort. Arguments for the operationalization of the selfdiscrepancy process in research designs are put forward. In studies tracking changes over time, it is suggested that the inclusion of a variable measuring the current L2 self could provide important insights into self-discrepancy trajectories, facilitate the investigation of motivational dynamics, and bring greater sensitivity to interventiondesign.
\end{abstract}

\section{Key words}

L2 motivation; self-discrepancies; possible selves; self-revision; global English 


\section{Introduction}

The reframing of L2 motivation as a self system constitutes a "watershed" in L2 motivation research (Dörnyei \& Ryan, 2015, 73). Achieving paradigmatic status, it has stimulated an unprecedented surge in empirical research, and generated a range of practitioner-oriented publications. However, the motivation-generating process at the heart of Dörnyei’s theory has received little attention (Dörnyei \& Ryan, 2015). Moreover, although L2 motivation research is witnessing a dynamic turn, and the self-guides of the L2 Motivational Self System (L2MSS) are conceptualized as dynamic constructs (Henry, 2013), the relationship between current and future self-guides is not operationalized in the L2MSS model. This design anomaly is not without consequences. Changes in learner motivation need not necessarily be a consequence of changes in the ideal L2 self; shifts in motivational intensity can equally be caused by changes to the current L2 self, or by changes in both the current and the ideal L2 selves. As a step in the process of methodological development, this article explores the fundamental dynamic at the heart of Dörnyei’s conceptualization of L2 motivation.

The structure of the article is as follows. A framing for the research is first presented. This begins with an examination of Higgins' (1987) theory of self-discrepancy and is followed by discussion of the origins of the L2MSS, research on the ways in which possible selves are revised, and longitudinal research in L2 motivation. The purpose of the study, which is to test hypotheses relating to differences in students' self-discrepancies in different school grades and their effects on a criterion measure, is then set out. Following an outline of the method and presentation of the results, the discussion focuses on methodological, empirical and pedagogical arguments favouring the operationalization of current-ideal self-discrepancies in the L2MSS.

\section{Self-conflicts and motivation}

And to my hero. That's who I chase. Now, when I was 15 years old, I had a very 
important person in my life come to me and say ‘who’s your hero?’ And I said, 'I don’t know, I gotta think about that. Give me a couple of weeks.' I come back two weeks later, this person comes up and says 'who’s your hero?' I said, 'I thought about it. You know who it is? It's me in 10 years.' So I turned 25. Ten years later, that same person comes to me and says, 'So, are you a hero?’ And I was like, 'not even close. No, no, no.' She said, 'Why?’ I said, 'Because my hero’s me at 35.' So you see every day, every week, every month and every year of my life, my hero’s always 10 years away. I’m never gonna be my hero. I'm not gonna attain that. I know I'm not, and that's just fine with me because that keeps me with somebody to keep on chasing. ${ }^{i}$

So are the words of academy award-winning actor Matthew McConaughey who, in his 2014 Oscars gala address, broke with convention by thanking himself. McConaughey’s perception of how the motivation to develop his career arose from a need to "keep on chasing" the person of his dreams encapsulates the essence of one of the most fundamental recognitions in psychology; that inconsistencies and conflicts between different elements of the self tend to create problems. In his seminal paper setting out the theory of self-discrepancy, Higgins (1987) explains how the idea that conflicting or incompatible beliefs about the self are likely to cause discomfort has a long history. Referencing many of the classic theories of early psychology (e.g. Allport, 1955, James 1890/1948, Mead, 1934), Higgins describes how human behaviors can be understood as responses to emotional discomfort triggered by selfconflicts. As he makes clear, although there are a multitude of different types of selfknowledge incompatibilities found in the literature, emotional responses to conflicts typically include experiences of tension, unease, pressure, stress and discomfort.

In the same way that there can be conflicts between a person's different self-concepts - a common difference being between an individual's own perception of self and that they perceive to be held by others (Mead, 1934) - conflicts can also exist between a current self 
and a potential or 'possible’ self. As Markus and Nurius (1986) explain, possible selves are domain-specific, future-oriented forms of self-knowledge pertaining to how people think about their potential and their future. Collected together, possible selves create unique coalitions of future-oriented self-knowledge that guide a person’s current behavior.

Motivated behavior arises when discrepancies are experienced between an actual self (i.e. McConaughey’s view of himself in the present), and a possible self (his hero). Higgins (1987) identifies three agentic responses through which discomfort-generating selfdiscrepancies can be managed. These are, respectively, (i) by the actual self becoming less discrepant from the potential self, (ii) by the potential self becoming less discrepant from the actual self, and (iii) as a result of processes where the accessibility of self-discrepancies is reduced, that is to say by the person taking actions to avoid situations where the selfdiscrepancy becomes salient.

It is the first of these scenarios that generates goal-directed motivation. However, motivational intensity will be sustained only in so far as the target - the potential self - also shifts in a forward or upwards direction. That is, like McConaughey's hero, the potential self needs to continue to remain sufficiently distant. However, if over time the potential self doesn't keep pace with developments in the actual self, motivational energy will deplete as the discrepancy shrinks. Surprisingly, this central dynamical process has received little attention in psychology, and it is only now that work carried out by Carroll and his associates (Carroll, 2014; Carroll, Agler \& Newhart 2015; Carroll, Shepperd \& Arkin, 2009) is beginning to more closely examine the ways in which self-concept revisions take place.

\section{Self-concept revisions}

Returning to Higgins' three ways of managing self-discrepancies, leaving aside the avoidance strategy, it is clear that discomfort can be influenced by revision of either the current or the potential self, or revisions to both. For example, measures can be taken to enhance the current 
self and to bring it psychologically closer to the potential self. Alternatively, the person could re-envision the future and, as a consequence, revise or even abandon a desired possible self. Of course, the forms that discrepancy-ameliorating trajectories take are complex, iterative processes. Indeed, other than the total abandonment of a potential self, resolutions to selfdiscrepancy problems will rarely be fully accomplished. Moreover, processes of engaging with conflicts stemming from discrepancies involving current and future self-conceptions central to the individual's core sense of self are likely to be enduring, sometimes taking place over timescales as long as the lifespan itself.

In recent work on processes of self-revision, Carroll and colleagues (2015) have developed a sophisticated model of self-revision processes. Two characteristic dynamical patterns are identified. In one pattern, an individual with a good awareness of his/her true core competencies is able to use these to upwardly revise possible selves in a systematic manner. Similarly to Fredrickson’s (2003) broaden-and-build theory of positive emotions, Carroll and his colleagues (2015) argue that positive emotional experiences "roll over to compound the positive emotions evoked by new possible self-success in an upward spiral of growth” (486). This is the essence of the experience described by McConaughey in striving to attain an ideal self that, like the fruit for Tantalus, is always there, but also constantly out of reach.

In the second pattern the spiral is downwards. The downwards revision of a desired possible self takes place when the self-image is challenged, and when activities expected to function in ways that reduce the discomfort do not consistently deliver successes that are hoped for. As Carroll and colleagues (2015) explain, when "possible self-failures increase and ultimately outnumber successes”, they can slowly converge into a broader pattern of failure (486). In such situations, the desired self is always uncomfortably distant, leading over time to reassessment and gradual weakening.

So far, processes of self-revision have not been addressed in L2 motivation research. As in 
psychology generally, greater emphasis has been placed on the role of vision, and processes involved in generating, enhancing and maintaining motivational images of future L2 use (Dörnyei \& Ryan, 2015). While understandable in that it is the visionary dimension that makes possible selves unique among motivational constructs, and it is around future visions that motivation-enhancing interventions are created, the lack of interest in discrepancies is unfortunate; little is known about the processes that generate tensions between how a person feels he/she is as a TL-speaker and how he/she wants to be, or about the possible patternings of L2 self-discrepancies.

\section{The missing person in L2 motivation?}

As is well-documented, the L2MSS was a response to growing dissatisfaction with Gardner's classic concept of integrativeness. However, it is important to note that in developing the model, Dörnyei (2005) drew on Higgins’ (1987) and Markus and Nurius’ (1986) theorizing, and not their empirical work. Consequently, the L2MSS is something of a hybrid. In essence, the L2MSS involves the import of a ground-breaking conceptual innovation - the conceptualization of L2 motivation as a "complex interplay of current and imaginative selfidentities” (Dörnyei, 2009b, 213) - into a pre-existing and rather different empirical tradition.

In the empirical work by Higgins, Markus and their respective associates, selfdiscrepancies are measurable constructs. While in Markus and Nurius’s (1986) work participants are asked whether a particular self-concept describes them currently, and, if so, whether it was also considered as a possible self, in Higgins’ research (1987) selfdiscrepancies are measured across a range of domains by examining matches/mismatches between participants’ actual and ideal self-states. However, unlike like these classic operationalizations, and the many variants to be found in the literature (for examples and discussion of methodological issues see Packard \& Conway, 2006), Dörnyei’s model lacks a component measuring the participant's current L2 self-concept. Consequently, while self- 
discrepancies are implied, and Dörnyei consistently makes clear that for motivation to arise the ideal L2 self "should not be regarded as comfortably within reach” (Dörnyei \& Ryan, 2015, p. 92), the L2MSS does not enable measurements to be made. The reasons for this are historical. With the aim of broadening the content domain of Gardner's classic concept so as to achieve better explanatory power across a broader range of contexts, Dörnyei and Csizér (2002) demonstrated that an internal identification with an imagined future L2-speaking self was superior to an external identification with real (or imagined) TL-speakers.

In this and subsequent work, an 'ideal L2 self' scale is generally inserted into AMTBmodelled questionnaires (e.g. Ryan, 2009; Taguchi, Magid \& Papi, 2009). Over time, these studies have functioned as templates for subsequent research, and there are now well in excess of 100 published studies using the L2MSS model. ${ }^{\text {ii }}$ In one of very few papers with a focus on measurement issues associated with the L2MSS, MacIntyre and his colleagues (2009) astutely make the point that the potential of a possible selves approach lies "in the comparison of present and future states” (209). However, to the best of our knowledge, the only studies where self-discrepancies are actually operationalized is the aforementioned study by MacIntyre and colleagues, and the study by Henry and Cliffordson (2016). ${ }^{\mathrm{iii}}$

\section{Patternings of self-revision}

While the problems associated with the failure to operationalize self-discrepancies are less apparent in cross-sectional research, this is not so in research with a longitudinal dimension. Language learning is fundamentally about time. Not only do changes take place to the challenges facing learners in developing skills during learning, but for researchers the varying demands confronting learners can only be meaningfully interpreted within a longitudinal perspective (Ortega \& Iberri-Shea, 2005). For the L2MSS, two patterns of self-discrepancy dynamic might map onto recognized motivational trajectories.

One pattern involves a process of a steady upward revision of both the ideal and the 
current L2 self. This pattern would be characteristic of motivated learners who are able to sustain energy over time, such as those experiencing a directed motivational current (Dörnyei, Henry \& Muir, 2016). The other pattern is generally characteristic of demotivated learners (Dörnyei \& Ushioda, 2011). Here, the downward revision of the ideal L2 self functions to ease any tension the individual might once have felt (for example at the outset of a program of study), the failure to fully engage with learning opportunities being a common response.

In studies surveying language learners' motivation over time, findings from prospective panel studies (e.g. Chambers 1999; Henry, 2009; Lamb 2007) and cross-sectional 'trend' studies (e.g. Henry \& Apelgren, 2008; MacIntyre et al., 2002; Williams, Burden \& Lanvers, 2002), all show that motivation generally wanes, and that different sources of L2 motivation can develop differently (Dörnyei \& Ushioda, 2011). Generally, the picture emerging is of an initial enthusiasm at the start of language programs which thereafter diminishes, sometimes rapidly (see e.g. Chambers, 1999; Gardner \& Smythe, 1975; Heining-Boynton \& Haitema, 2007; MacIntyre et al., 2002; Phillips \& Filmer-Sankey, 1993; Williams et al., 2002). For example, in studies carried out with UK school students learning foreign languages, Chambers (1999) and Williams and colleagues (2002) both found a pattern of declining motivation, especially towards the end of compulsory school. Similar results have been found in studies carried out in Canada (Gardner \& Smythe, 1975; MacIntyre et al., 2002), China and Japan (Tachibana et al., 1996), and Indonesia (Lamb, 2007).

Interestingly, in studies where identity-oriented measures have been included, findings reveal that these variables are generally more stable than variables that measure attitudes to the learning situation or instrumental motives. For example, Gardner and colleagues (2004) found that for first-year Anglophone university students in Canada learning French, integrative motivation showed greater stability over a year of study than variables relating to 
the learning situation. Similarly, in an Indonesian study, Lamb (2007) found that while positive attitudes to English and expectations of success were maintained over the first 20 months of junior high school, attitudes toward the learning experience deteriorated.

When ideal L2 self variables have been included in designs, similar results have been found. Surveying first-year university students studying German over the course of an academic year, Busse (2013) found no changes in ideal L2 selves or in the strength of correlations between the ideal L2 self and effort, while at the same time students' selfefficacy beliefs declined significantly. In surveying the strength of ideal selves for French, German and Spanish learnt as L3s over a three-year period of secondary school, Henry (2009) similarly found ideal selves to be relatively stable compared to other independent variables, particularly attitudes to the learning situation.

\section{Ideal L2 selves are generally robust}

Although there are not a sufficient number of studies to make categorical claims, it appears that while the ideal L2 self remains relatively robust over periods of learning, other independent variables tend to decline. Further, measured as a dependent variable, motivation is also generally found to decline. Of course, there a number of reasons why variables such as e.g. self-efficacy beliefs (Busse, 2013) and attitudes to the learning situation (Henry, 2009; Lamb, 2007) display greater variability than the ideal L2 self. However, it is also possible that, in only measuring one part of a dynamical relationship, a distorted picture is gained, and that motivation attributable to the vision of a future TL-speaking self may not be as stable as might appear. This is what Henry and Cliffordson (2016) have suggested. Arguing that designs incorporating measures of the Ideal L2 Self only capture one element of a dichotomic

relationship, they demonstrate that it is the discrepancy between current and ideal selves that properly accounts for variance on a criterion measure, using this finding to explain why, across different contexts, ideal L2 selves of a similar strength can have widely divergent 
correlations with criterion variables.

\section{Purpose}

Echoing MacIntyre and colleagues’ (2009) early concerns about the appropriate operationalization of motivational processes in the L2MSS, Dörnyei and Ryan (2015) argue that motivation needs to be understood in terms of the size and nature of the gap between current and ideal L2 selves. In a research design including items capturing a participant's current L2 self, and then measuring the discrepancy between the current L2 self and the ideal L2 self and its effect on a criterion variable, Henry and Cliffordson (2016) have demonstrated the importance of these arguments. Given that previous longitudinal research provides a general picture of motivational declines, yet relative stability in measures of the ideal L2 self, there is good reason to investigate the strength of the ideal L2 self in relation to the strength of the current L2 self at different stages in students' education. Replicating the design used by Williams and her colleagues (2002), who measured motivational factors including attitudes, agency and identity for independent samples of students in schools grades 7 and 9, and were thus able to explore differences in motivation for students of different ages, the purpose of the current study is to establish whether the nature of the discrepancy between the current L2 self and the ideal L2 self differs between a cohort of younger students (in grade 7) and a cohort of older students (in grade 9), and whether differences affect explained variance on a criterion measure.

In line with the research previously discussed, it was first hypothesized that while the strength of the ideal L2 self would be similar for both cohorts, its effect on motivation would be less in grade 9:

H1a That scores on the ideal L2 self will be similar for the grade 7 cohort and the grade 9 cohort

H1b That the explained variance on the criterion measure of intended effort attributable to 
the ideal L2 self will be greater for the grade 7 cohort than the grade 9 cohort

In a second stage, the same hypotheses were tested again, this time in relation to a variable created to capture the discrepancy between ideal L2 self and the current L2 self:

H2a That the discrepancy between the current L2 self and the ideal L2 self will be greater for the grade 7 cohort than for the grade 9 cohort

H2b That the explained variance on the criterion measure of intended effort attributable to the current-ideal discrepancy will be greater for the grade 7 cohort than for the grade 9 cohort.

\section{Method}

\section{Setting}

In Sweden “an overwhelming Anglicization” (Cabau 2009, 134) has taken place. English is highly constituent in many young people’s lives (Henry et al., 2017, advance access) and can be regarded as functioning as "a second language in the Swedish daily living environment" (Cabau, 2009, 134). People in Sweden have high levels of proficiency in English, more 14- to 15-year-old students than in any other European country achieving CEFR B2 'upper intermediate user’ level for receptive skills (European Commission, 2012). Students have positive beliefs about their capacity to use English, and a large majority of students gain passing grades or higher in English at both secondary and upper secondary levels. English is a core subject in the Swedish curriculum and, for most students, formal instruction begins in the first grade (age 7). By the $6^{\text {th }}$ grade (age 12), students generally have around two hours of instruction per week. However many students believe that much of what they have learned in English is a consequence of out-of-school encounters, and students often describe English classes as mundane and lacking challenges. They also report being more comfortable when using English outside school than in the classroom (Henry, 2014).

\section{Design and participants}


The study replicates the design used by Williams and her colleagues (2002), where a multiitem questionnaire was administered to students in grades 7 and 9 at different schools $(\mathrm{n}=$ 228), the aim being to identify trends related to age. In the current study participants were from seven secondary schools in the western part of Sweden $(n=291)$. As in the study by Williams et al. (2002), students were evenly divided between the two grades; 145 in grade 7 $(\mathrm{m}=44.1 \%$; $\mathrm{f}=55.9 \%)$, and 146 in grade $9(\mathrm{~m}=41.8 \% ; \mathrm{f}=58.2 \%)$. In this design, each grade represents an independent sample of participants and allows consideration of different stages of a common learning trajectory (Keeves, 1994). The distribution of participants is set out in Table 1.

Table 1, Distribution of participants in grades at school

\begin{tabular}{l|ccr}
\hline \multicolumn{1}{l}{ School } & $N$-tot & Grade & Grade 9 \\
\hline School A & 86 & 20 & 66 \\
School B & 42 & 16 & 26 \\
School C & 38 & 38 & 20 \\
School D & 36 & 16 & 19 \\
School E & 35 & 16 & 15 \\
School F & 27 & 27 & 146 \\
School G & 27 & 12 & \\
Total & 291 & 145 & \\
\hline
\end{tabular}

\section{Instrument and procedures}

The questionnaire was identical to the instrument developed by Henry and Cliffordson (2016), and contained scales measuring the ideal L2 self and the current L2 self (as independent variables), and intended effort in school (as the dependent variable). Items measuring the ideal L2 self were mirrored-formulations of items measuring the current L2 
self. The questionnaire was administered to students in their ordinary classrooms during the autumn of 2015 and in early spring 2016. At all times class-teachers were present.

\section{Data and analyses}

The dependent variable Intended Effort in School, and the independent variables Current L2 Self and Ideal L2 Self were measured using five-point Likert scales. Descriptive statistics can be found in Table 2, where items for each latent variable are presented by grade. In order to test the two hypotheses, data was analyzed using structural equation modelling (SEM). The SEM was conducted using Mplus 6.1 (Muthén \& Muthen, 1998-2010) under the STREAMS (Gustafsson \& Stahl, 2005) environment, and multi-group modelling was performed to test for group differences. The items used in the current analyses can be found in Appendix One.

\section{Missing data}

Even though there is only a small amount of missing information in the data, the missing data modeling procedure implemented in the Mplus program was used (Muthén, Kaplan \& Hollis, 1987). Data is assumed to be missing at random (MAR) which implies that missingness is allowed to depend on observed values but not on missing values (Shaefer \& Graham, 2002). For patterns of missing data, see Table 2.

Table 2, Descriptive statistics

\begin{tabular}{|c|c|c|c|c|c|c|c|c|}
\hline & \multicolumn{4}{|c|}{ Grade 7} & \multicolumn{4}{|c|}{ Grade 9} \\
\hline & $N$ & Missing & $m$ & sd & $N$ & Missing & $m$ & $s d$ \\
\hline & \multicolumn{4}{|c|}{$N$} & \multicolumn{3}{|c|}{$N$} & \\
\hline \multicolumn{9}{|c|}{ Current } \\
\hline Cu 1 & 142 & 3 & 3.85 & 1.03 & 146 & 0 & 3.91 & 0.95 \\
\hline $\mathrm{Cu} 2$ & 142 & 3 & 3.82 & 1.13 & 146 & 0 & 3.98 & 1.03 \\
\hline $\mathrm{Cu} 3$ & 142 & 3 & 3.78 & 1.09 & 146 & 0 & 4.01 & 1.08 \\
\hline
\end{tabular}




\begin{tabular}{|c|c|c|c|c|c|c|c|c|}
\hline $\mathrm{Cu} 4$ & 139 & 6 & 3.97 & 1.04 & 145 & 1 & 4.07 & 1.03 \\
\hline Cu 5 & 141 & 4 & 3.57 & 1.11 & 145 & 1 & 3.73 & 1.89 \\
\hline $\mathrm{Cu} 6$ & 142 & 3 & 4.02 & 1.09 & 144 & 2 & 4.28 & 0.96 \\
\hline Total & 138 & 7 & 3.85 & 0.93 & 143 & 3 & 4.02 & 0.86 \\
\hline \multicolumn{9}{|l|}{ Ideal } \\
\hline Id 1 & 141 & 4 & 4.31 & 0.85 & 146 & 0 & 4.20 & 0.98 \\
\hline Id 2 & 140 & 5 & 4.10 & 1.15 & 145 & 1 & 4.08 & 1.09 \\
\hline Id 3 & 141 & 4 & 4.22 & 1.00 & 146 & 0 & 4.16 & 1.01 \\
\hline Id 4 & 145 & 0 & 4.18 & 0.96 & 146 & 0 & 4.03 & 1.01 \\
\hline Id 5 & 143 & 2 & 3.91 & 1.10 & 144 & 2 & 3.93 & 1.06 \\
\hline Total & 138 & 7 & 4.14 & 0.86 & 143 & 3 & 4.09 & 0.85 \\
\hline \multicolumn{9}{|l|}{ Effort } \\
\hline Ef 1 & 145 & 0 & 3.16 & 1.22 & 144 & 2 & 3.22 & 1.16 \\
\hline Ef 2 & 144 & 1 & 3.38 & 0.95 & 146 & 0 & 3.21 & 1.12 \\
\hline Ef 3 & 142 & 3 & 2.63 & 1.13 & 143 & 3 & 2.63 & 1.26 \\
\hline Ef 4 & 145 & 0 & 2.80 & 1.06 & 146 & 0 & 2.71 & 1.12 \\
\hline Total & 141 & 4 & 3.00 & 0.89 & 141 & 5 & 2.93 & 0.95 \\
\hline
\end{tabular}

\section{Goodness of fit}

The $\chi^{2}$ goodness-of-fit test, the root mean square error of approximation (RMSEA) and the comparative fit index (CFI) were used as measures of model fit. When the $\chi^{2}$ goodness-of-fit test did not produce significant results, additional goodness-of-fit measures were not necessary. However, when the $\chi^{2}$ goodness-of-fit test indicated a significant result, the RMSEA and CFI were used. The RMSEA is an established tool for evaluating model fit since it takes both the number of observations and the number of free parameters into account 
(Brown, 2006). Values below 0.05 generally indicate a close fit and values between 0.05 and 0.08 indicate an acceptable model fit (Browne \& Cudeck, 1993). The values of CFI can range from 0 to 1 , where values equal to or larger than 0.95 indicate a good model fit. The CFI is based on a comparison of the $\chi^{2}$ value of the model and the $\chi^{2}$ of the null model.

\section{Results}

\section{Measurement models for Effort, Current L2 Self and Ideal L2 Self}

In a first step, measurement models for Current L2 Self (Curr), Ideal L2 Self (Ideal) and Effort (Effort) were tested to confirm the factor loadings, and to test the model fit for the grade 7 cohort and the grade 9 cohort respectively. The models are referred to as Model A1-2 (Curr), Model B1-2 (Ideal) and Model C1-2 (Effort), and are shown in Figures 1-3. These measurement models exactly mirror the models constructed by Henry and Cliffordson (2016). The model fit indices for the measurement models were good for both grade 7 and for grade 9 (Table 3) and the models yielded non-significant $\chi^{2}$ values. The factor loadings were significant for all models for both the grade 7 and grade 9 cohorts, and ranged between .57 and .91 for Effort, between .70 and .93 for Current, and between .57 and .88 for Ideal (Figures 1-3). However, for Effort a covariance between the error variance for item 2 and item 4 was defined for grade 7, this in order to obtain an acceptable model fit. This was not necessary for grade 9. The measurement models were also tested in multi-group modelling in order to investigate mean differences for the latent variables Current (Model A3), Ideal (Model B3) and Effort (Model C3) between the grade 7 cohort and the grade 9 cohort. The mean differences mirrored the descriptive results (Current, 0.16, Ideal -0.11, Effort -0.13). The largest difference was for Current. 


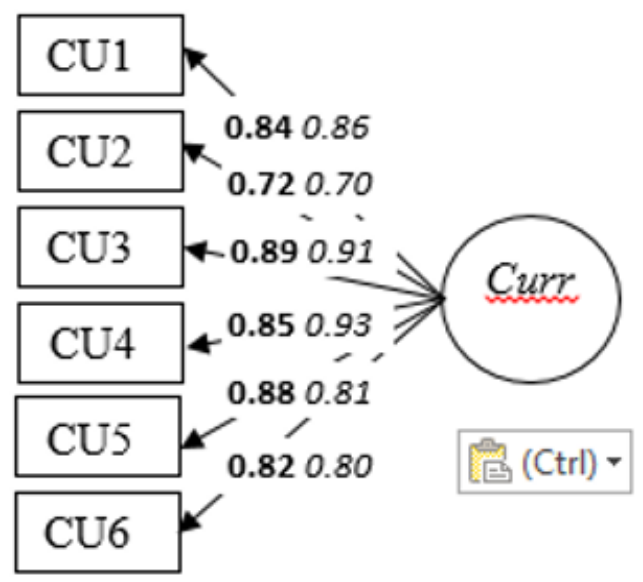

Note: grade 7: bold, grade 9: italics

Figure 1, Model A1-2 - Measurement model Current L2 Selves

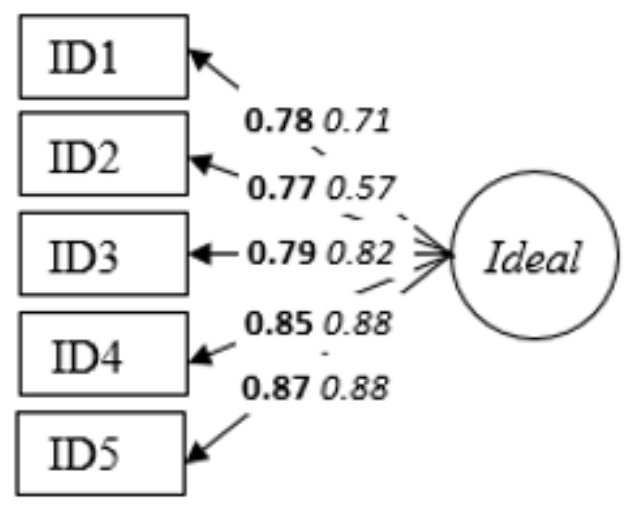

Note: grade 7: bold, grade 9: italics

Figure 2, Model B1-2 - Measurement model Ideal L2 Selves

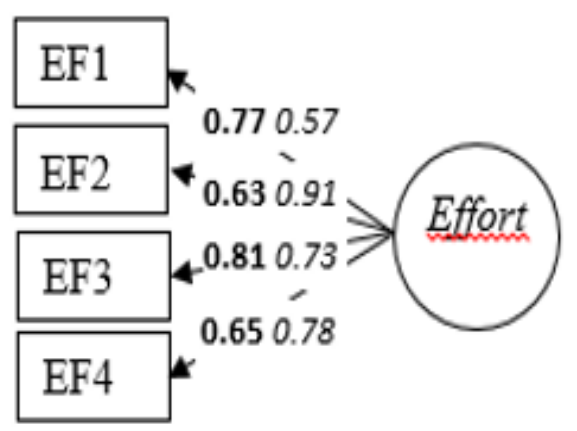

Note: grade 7 - bold, grade 9-italics; covariance between error variance for item 2 and 4 for grade 7

Figure 3, Model C1-2 - Measurement model intended effort in school 


\section{Hypotheses 1a and $1 b$}

As indicated by the mean values for the latent variables, almost no differences are found for Ideal when the grade 7 cohort is compared with the grade 9 cohort. This might imply that the relation between Ideal and Effort would also be stable between the two grades. To test this relation, a multi-group model was constructed for a relation between Ideal and Effort for the grade 7 cohort, and for the grade 9 cohort (Model D1, Figure 4). In this model all parameters are allowed to vary between groups. Model fit indices indicated a good model fit (Table 3), and all factor loadings were significant. The relation between Ideal and Effort was significant for both grades. However the relation was larger for the grade 7 cohort (.55), than for the grade 9 cohort (.23) (Figure 4). In order to test whether these differences are significant, it is necessary to compare the non-constrained model with a model where the relation between Ideal and Effort is constrained to be equal between groups (Model D2) (Model fit indices can be found in Table 3). When the two models are compared, significant differences are revealed $(\Delta \chi 2=35.70(\mathrm{df} 2))$, the constrained model having a significantly worse model fit. This indicates that the relation between Ideal and Effort is indeed different for the grade 7 cohort and the grade 9 cohort. Thus, even though there are no significant mean differences for Ideal when the grade 7 cohort is compared with the grade 9 cohort, the explanatory power of Ideal for Effort differs significantly between the two cohorts.

The decreasing explanatory power of Ideal L2 Self between the grade 7 cohort and the grade 9 cohort could of course be due to a number of untested variables. However, we might also expect the reduction in explanatory power of Ideal L2 Self to be caused by changes in the self-discrepancy (i.e. the gap between the current L2 self and the ideal L2 self). In a previous study by Henry and Cliffordson (2016) with first-year upper secondary students, it was suggested that, in comparison with other settings, the lower correlation between the Ideal L2 Self and Effort in a Swedish sample was likely explained by a smaller gap between the 
current L2 self and the ideal L2 self. In this study it was found that about 15 percent of the variation in Effort could be explained by the discrepancy between the current L2 self and the ideal L2 self. Thus, in the current study, a reasonable hypothesis is that the decreased explanatory power of the ideal L2 self in grade 9 might best be explained by changes in the current L2 self that result in a decreased current-ideal discrepancy.

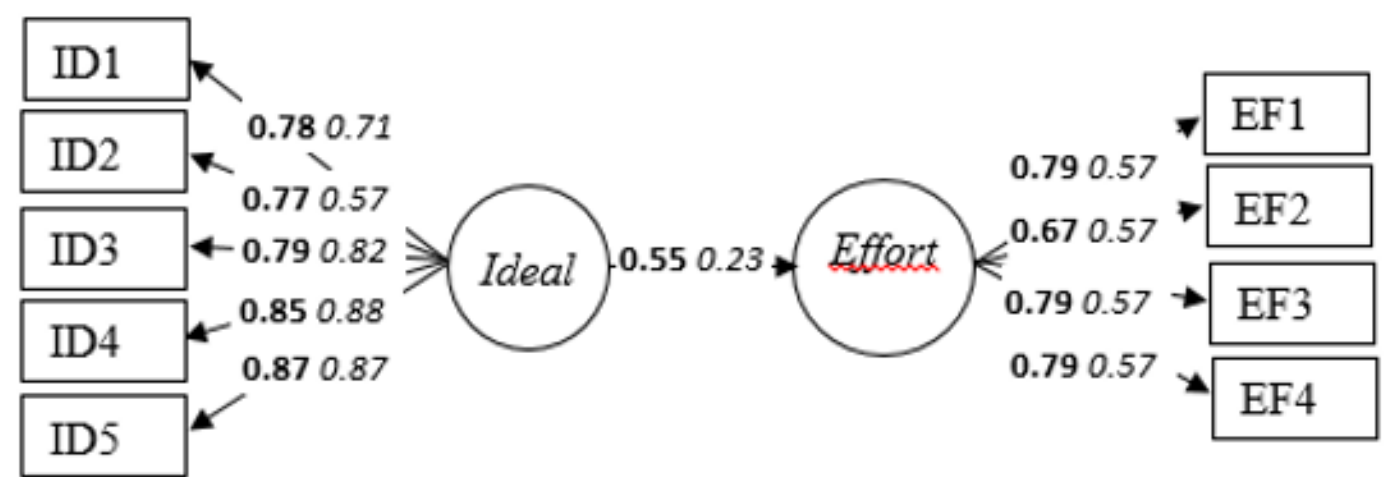

Note: grade 7- bold, grade 9 - italics; covariance between error variance for item 2 and 4 for grade 7 Figure 4, Model D1-2 - Relation between Ideal L2 Self and Effort

\section{Hypotheses $2 a$ and $2 b$}

In order to test this hypothesis, a model including Current L2 Self, as well as a latent variable representing the discrepancy between Current L2 Self and Ideal L2 Self was created. To measure the Current L2 Self-Ideal L2 Self discrepancy, a nested factor model was set up. This model is identical to the model developed by Henry and Cliffordson (2016). A nested factor model implies that a general latent variable is identified for a domain of observations, as well as narrow latent variables which account for differences on a subset of variables. This makes this approach suitable for identifying the discrepancy between the Current L2 Self and the Ideal L2 Self. In the present study, the nested factor model includes one general latent variable (Gen), which represents the variance common to Current and Ideal L2 Self, and one narrow latent variable (Diff), which represents the discrepancy between Current L2 Self and 
Ideal L2 Self, and which is in turn related to the latent variable measuring intended effort in school (Effort). The model was tested for both the grade 7 and grade 9 cohorts in a multigroup model (Model E1, Figure 5).

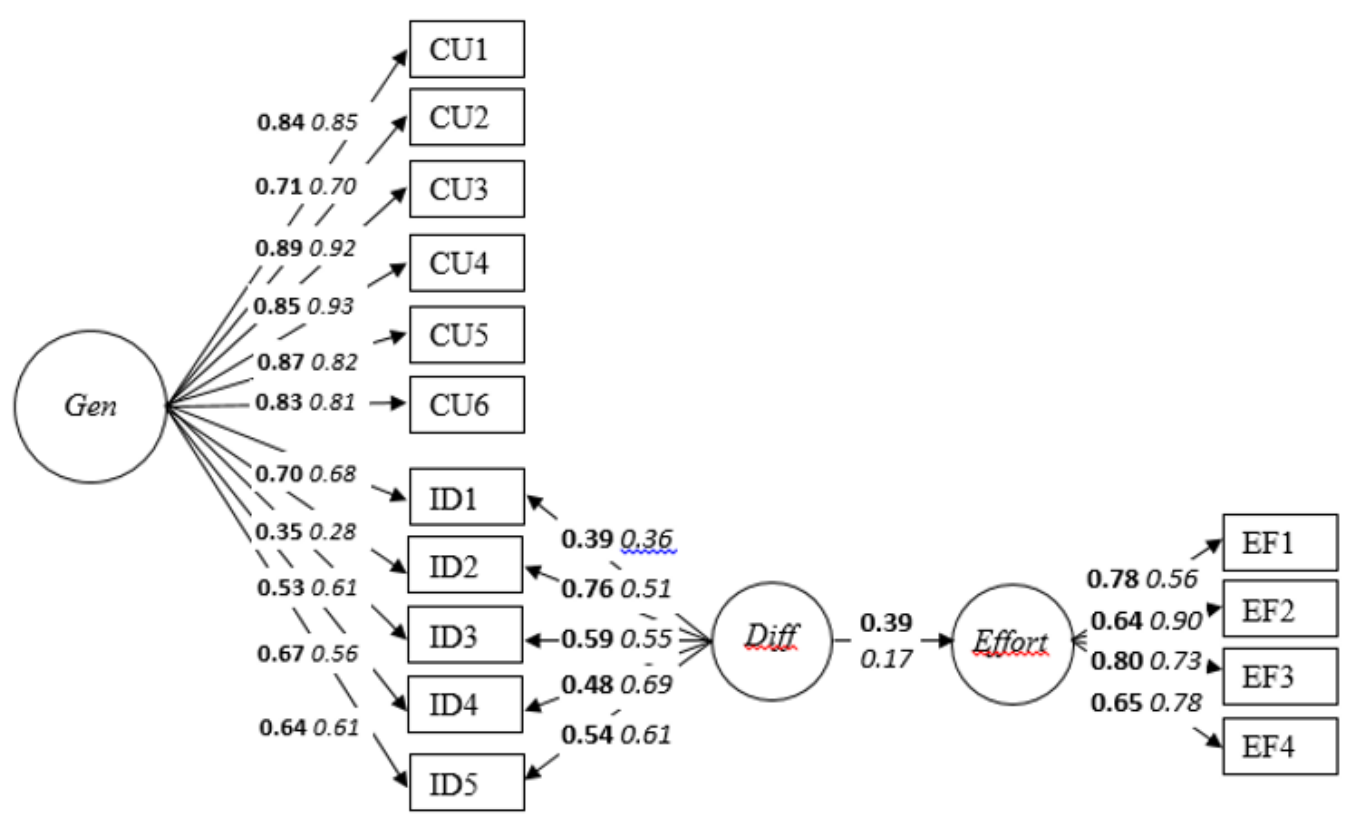

Note: grade 7 - bold, grade 9 - italics; covariance between error variance for item EF2 and EF4 for grade 7.

Figure 5, Model E1 - Nested diff-model

The mean difference for the latent variable Diff was found to be -0.32 , t-value -2.55 . This indicates that the difference between Current and Ideal L2 self is greater for the grade 7 cohort than for the grade 9 cohort, and that this difference is significant. The model fit was acceptable (Table 3) and all factor loadings were significant. Interestingly, the relation between Diff and Effort was not significant for the grade 9 cohort. In fact, the relation between Diff and Effort was .39 for the grade 7 cohort, and .17ns for the grade 9 cohort. This indicates that while for the grade 7 cohort the discrepancy between the Current L2 Self and the Ideal L2 Self accounts for about 15 percent of the variance, for the grade 9 cohort it does not explain any of the variance. 
Table 3, Model fit indices for model $A-E$

\begin{tabular}{|c|c|c|c|c|c|c|}
\hline Model & Grade & $X^{2}$ & $d f$ & $p$-value & $C F I$ & RMSEA \\
\hline A1 & 7 & 14.26 & 9 & 0.11 & & \\
\hline A2 & 9 & 10.99 & 9 & 0.28 & & \\
\hline A3 & $7-9$ & 31.52 & 23 & 0.11 & & \\
\hline B1 & 7 & 9.00 & 5 & 0.11 & & \\
\hline B2 & 9 & 6.80 & 5 & 0.24 & & \\
\hline B3 & $7-9$ & 20.78 & 14 & 0.11 & & \\
\hline $\mathrm{C} 1$ & 7 & 0.30 & $1 *$ & 0.58 & & \\
\hline $\mathrm{C} 2$ & 9 & 0.58 & 2 & 0.75 & & \\
\hline C3 & $7-9$ & 3.18 & $6^{*}$ & 0.78 & & \\
\hline D1 & $7-9$ & 86.35 & 58 & 0.01 & 0.97 & 0.058 \\
\hline D2 & $7-9$ & 122044 & 60 & 0.00 & 0.94 & 2uld \\
\hline E1 & $7-9$ & 338.29 & 179 & 0.00 & 0.95 & encte \\
\hline E2 & $7-9$ & 342.63 & 180 & 0.00 & 0.95 & 0.079 \\
\hline
\end{tabular}

To investigate whether the results relating to the relation between Diff and Effort between the two cohorts are significant, further modeling was required. This was done by comparing two models, one where invariance between groups is not assumed (i.e. where all parameters are allowed to vary between groups), and one where invariance is assumed. First, the model where all parameters vary between groups (Model E1, above) was compared to a model where the relation between Diff and Effort is constrained to be equal between groups (Model E2). When the model fit for model E1 and model E2 were compared, significant differences were found ( $\Delta \chi^{2}=4.34(\mathrm{df} 1)$ ), (see Table 3 for Model fit indices). This implies that equality between groups cannot be assumed for the grade 7 cohort and for the grade 9 cohort for the 
relation between Diff and Effort. This in turn means that the discrepancy between Current L2 Self and Ideal L2 Self explains why, when compared with the grade 7 cohort, the variance in Effort is non-significant for the grade 9 cohort, and that this is a consequence of the smaller Current L2 Self-Ideal L2 Self discrepancy in the grade 9 cohort.

\section{Summary}

To summarize; first we showed that, for both grade 7 and grade 9, the Current L2 Self, the Ideal L2 Self and Effort could be captured by the measurement models (Models A, B and C). Using multi-group modelling, we then showed that there were mean differences for the Current L2 Self between the two grades, it being higher in grade 9. Then we showed that there were differences in the relation between Ideal L2 Self and Effort between grade 7 and 9 (Model D). Finally, using a latent variable to capture the difference between Current L2 Self and Ideal L2 self, we showed that relation between this variable and Effort was greater in grade 7 (Model E1 and E2).

\section{Discussion}

The results reveal a picture of a dynamic process where the gap between the current L2 self and the ideal L2 self is smaller in grade 9 compared to grade 7 . This shrinking discrepancy is shown to have a negative impact on students' motivational approaches to classroom learning. Although both ideal and current L2 selves are likely to change over time, the findings suggest that change in current selves might be generally greater than change in ideal selves. In this light, measurement of the target construct alone becomes problematic since the element that may be most influential in determining motivational intensity, and which is most susceptible to change, is obscured. Set against the trend to more widely apply complex dynamic systems (CDS) approaches in understanding fluctuations in L2 motivation (Dörnyei, MacIntyre \& Henry, 2015; Hiver, in preparation; Hiver \& Al-Hoorie, 2016), the current results underscore the importance of operationalizing the motivation-generating mechanism at the heart of the 
L2MSS, not least when research objectives are focused on change over longer timescales.

In the setting for the current study, where English is centrally constituent in the lives of many young people, and in the context of the ongoing debate concerning the degree to which identities may be differently implicated in motivation to learn English in varying parts of the world (Ushioda, 2013; Ushioda \& Dörnyei, 2017), the results highlight the importance of mapping the development of the current L2 self. Because in many places English is now a basic social accomplishment, the question arises as to whether the learning process “necessarily entails some kind of self-transforming psychological investment or identity striving”, and whether skills-development “engages students’ identities in a potentially transformative sense” (Ushioda, 2013, 11). In contexts where English has been reframed as a general mode of communication and is a largely 'disembodied language’ unbound by particular cultures or values (Pinner, 2016), English-related identities are grounded in local as much as global practices. As Ushioda (2013) surmises, this means that idealized future identities might not be implicated in generating motivation in any major sense.

Similarly questioning the extent to which self-transformation processes play a role in motivation to learn English, Henry and Cliffordson (2016) suggest that in contexts where English has become a basic social literacy, people may develop hybrid rather than bicultural identities. Lacking the type of bilocular L2 identity theorized to be typical for learners of global English, and which comprises L1-mediated local components and L2-mediated global components (Lamb, 2004), young people growing up in places where English is ubiquitous in everyday life may not experience a future English-speaking self as radically different from their current English-speaking self. In the current study, results showing how a modest discrepancy in grade 7 had all but disappeared in grade 9 add further weight to these arguments.

Possible selves are fundamentally malleable (Markus \& Kunda, 1986), meaning that self- 
revision is a continual, ongoing process, changes in self-representations taking place in order to "improve their fit with environmental feedback” (Carroll et al., 2015, 483). For students learning English in Sweden, the period at the end of secondary school in grade 9 (age 15-16) may represent the nadir of processes where current L2 selves and ideal L2 selves become so similar that there is no longer any sense of a discrepancy. However, the diminishing of a selfdiscrepancy at one point in time does not preclude subsequent expansion at another. With growing maturity, and increasing concern with life-opportunities and career possibilities, processes of self-revision can take a different form as students progress through the school system. As Carroll and colleagues (2015) explain, the mental preparations that people make in advance of new life phases - for example when moving to higher educational level - can have a particularly important function in triggering self-revisions, the transition from secondary to upper secondary school being a juncture in life when revisions of possible selves are particularly likely.

If we compare the current results with those in the study by Henry and Cliffordson (2016) where, for a similar sample of first-year upper secondary students, identical latent variables and identical modelling techniques were used, an interesting pattern emerges. In Henry and Cliffordson (2016), the mean scores for the current L2 self and the ideal L2 self are higher than those here for both the grade 7 and the grade 9 cohorts. Moreover, if we compare discrepancies, we can see how for the upper secondary cohort in Henry and Cliffordson, the discrepancy accounted for an almost exactly similar proportion of variance on the criterion measure as did the grade 7 cohort in the current study (in both cases 15\%). This would suggest that in school contexts where English is highly-constituent in young people's lives, self-revision trajectories may be U-shaped. While it is not in any sense surprising that the current L2 self continues to strengthen as students proceed through the school system - the mean score for the current L2 self being progressively higher for all three cohorts (3.85, 4.02 
and 4.12 respectively) - the transition to upper secondary school appears to coincide with processes where the ideal L2 self undergoes an upward revision (compare the mean score of 4.09 for the grade 9 cohort in the current study with the mean score of 4.27 for the upper secondary cohort in Henry and Cliffordson). Notably, in the upper secondary cohort, the discrepancy is sufficient to generate discomfort and motivation.

\section{Conclusion and implications}

Stemming from the recognition that CDS provides "the epistemological basis for conceptualizing motivation” (Schumann, 2015, xv), an increasing range of quantitative, qualitative and mixed-methods approaches are being used to study L2 motivation (MacIntyre, Dörnyei \& Henry, 2015; Hiver, in preparation). Interestingly, while innovative designs are providing novel insights into dynamical processes taking place on varying timescales, in research using the L2MSS few of these innovations have made their presence felt. Reflecting on the currently paradigmatic status of the L2MSS, Dörnyei and Ryan (2015) identify a risk where conceptualizations of L2 motivation as a dynamic process do not penetrate down into the systems’ central constructs, the consequence being that the L2 motivational self-guides remain essentially static constructs representing “fixed 'targets’ or 'goalposts”” (94).

Operationalizing the self-discrepancy in the manner carried out in the present study by including the currently missing current L2 self, the dynamical element of self-revision could be incorporated into the L2MSS model. Specifically, in longitudinal designs the upwards and downwards revisions of ideal and current L2 selves and their effects on criterion variables could be plotted. Insights into the developmental processes of current and ideal L2 selves can reveal important motivational dynamics and characteristic patternings. For example, as Piniel and Csizér (2015) have shown, multivariate techniques such as latent growth modelling and longitudinal clustering procedures could be used to investigate the dynamical relations between different motivational variables. Such methods could be profitably employed in 
investigations of process relations between current and ideal selves. Because in CDS intraindividual variation is as important as inter-individual variation (van Dijk, Verspoor, \& Lowie, 2011), in small-sample, mixed-method designs, the use of techniques such as changepoint analysis could be used to identify when shifts take place in self-discrepancies, and the circumstances pertaining at such points in time could be explored using retrospective interviews (Hiver, 2016).

Nearly a decade ago, MacIntyre and colleagues (2009) argued that "one of the advantages of using a possible selves framework is looking at the integration of present and future selves and how various elements of those selves work together for an individual” (209). In this exploratory article, we have suggested that inclusion of measures of current L2 selves in research designs would have the effect of implanting the dynamical motivation-generating process central in Dörnyei’s pioneering conceptual work into the L2MSS model. Not only would this provide greater sensitivity to the different contexts in which L2s are learned, it would also facilitate the study of L2 motivation as a dynamical process. Informed by theories of the upward and downward revisions of possible selves (Carroll, 2014; Carroll et al., 2015), we suggest that, in designs with a longitudinal dimension, the inclusion of current selves could enable the mapping of complex motivational trajectories for both individuals and groups. This, in turn, could provide better opportunities to more closely align and fine-tune identity-focused motivational interventions with the needs of individual learners at different stages in their learning. For example, we have suggested that self-revision dynamics may have U-shape characteristics. Although the novelty of the study, the sample size, the operationalization of the current L2 self as a simple mirrored formulation of the ideal L2 self, and particular contextual factors all mean that caution needs to be exercised when proposing practical measures, it is clear that interventions might not be of the greatest value when discrepancies are either particularly large, or particularly small. Rather, interventions may be 
most effective at points where changes in self-revision processes might be anticipated. In the current context, because self-discrepancies appear to shrink after grade 7 and to expand again in upper secondary school, it may be in the phases of self-revision that coincide with educational transitions that measures designed to enhance students' ideal L2 selves might be most effective.

\section{Limitations and future research}

The design used in this study is a replication of the method used by Williams and her colleagues (2002), and draws on two independent samples that represent different stages in a common educational path. Like these researchers, we advise caution in interpreting the findings since they are the result of a cross-sectional, rather than a prospective panel study. A particular limitation in our study is that, for the grade 9 cohort, data was not collected at two of the schools. While the size of the sample and the predicted robustness of the ideal L2 self both indicate that cohort effects are unlikely, to provide further assurance that cohort effects were not affecting the results, the analyses reported on were also carried out for a sample where the schools with the missing grade 9 data were not included. The results of these analyses were in all respects the same as those previously presented.

Even when taking into consideration the general limitations associated with possible cohort effects (MacIntyre et al., 2002), the method used here can offer valuable insights into developmental patterns. In future research using a simultaneous cross-sectional method, two extensions of the current work would be of particular value. One would be to increase the size of independent samples so as to enable the investigation of self-discrepancy dynamics using salient grouping variables such as, for example, gender and multilingualism. The other would be to include personal identifiers in the questionnaires and, in a mixed-methods variant, to use cluster techniques and interviews to more closely explore L2 identity experiences associated with different self-discrepancy types. Here, retrodictive qualitative 
modelling methods (Chan, Dörnyei \& Henry, 2015) could provide useful insights into the dynamical development of self-discrepancy trajectories.

\section{Acknowledgements}

In addition to the students and teachers at the seven schools, we would like to thank Pia Sundqvist for her assistance in collecting some of the data.

\section{References}

Allport, G. W. 1955. Becoming. New Haven, CT: Yale University Press.

Browne, M. W., \& Cudeck, R. 1993. “Alternative ways of assessing model fit”. In Testing structural equation models, edited by Bollen, K. A., \& Long, J. S, 136-162. Newbury Park, CA: Sage.

Brown, T. A. 2006. Confirmatory factor analysis for applied research. New York: The Guilford Press.

Busse, V. 2013. “An exploration of motivation and self-beliefs of first year students of German”. System 41, 379-398.

Cabau, B. 2009. “The irresistible rise and hegemony of a linguistic fortress: English teaching in Sweden”. International Multilingual Research Journal 3, 134-52.

Carroll, P.J. 2014. “Upward Self-Revision: Constructing Possible Selves”. Basic and Applied Social Psychology, 36 (5), 377-385.

Carroll, P.J., Agler, R.A., \& Newhart, D.W. 2015. “Beyond cause to consequence: The road from possible to core self-revision”. Self Identity, 14(4): 482-498.

Carroll, P.J., Shepperd, J. A. and Arkin, R. M. 2009. “Downward self-revision: Erasing possible selves”. Social Cognition 27, 550-578.

Chambers, G. 1999. Motivating Language Learners. Clevedon: Multilingual Matters. 
Dörnyei, Z. 2009a. “The L2 Motivational Self System”. In Motivation Language Identity and the L2 Self, edited by Z. Dörnyei \& E. Ushioda, 9-42. Clevedon: Multilingual Matters.

Dörnyei, Z. 2009b. The Psychology of Second Language Acquisition. Oxford: Oxford University Press.

Dörnyei, Z. 2016. “From English language teaching to psycholinguistics: A story of three decades”. In Becoming and being an applied linguist: The life histories of some applied linguists, edited by R. Ellis, 119-135. Amsterdam: John Benjamins.

Dörnyei, Z., \& Ciszér, K. 2002. “Some dynamics of language attitudes and motivation: Results of longitudinal nationwide survey”. Applied Linguistics, 23, 421-462.

Dörnyei, Z., Henry, A. \& Muir, C. 2016. Motivational Currents in Language Learning: Frameworks for Focused Interventions. Routledge.

Dörnyei, Z., MacIntyre, P.D., \& Henry, A. Eds. 2015. Motivational dynamics in language learning. Bristol, UK: Multilingual Matters.

Dörnyei, Z. \& Ryan, S. 2015. The psychology of the language learner revisited. New York: Routledge.

Dörnyei, Z., \& Ushioda, E. Eds. 2009a. Motivation, Language Identity and the L2 Self. Clevedon: Multilingual Matters.

Dörnyei, Z., \& Ushioda, E. 2009b. ”Motivation, language identities and the L2 self: Future research directions”, In Motivation, Language Identity and the L2 Self, edited by Z. Dörnyei \& E. Ushioda, 350-356. Clevedon: Multilingual Matters.

Dörnyei, Z., \& Ushioda, E. 2011. Teaching and Researching Motivation (2nd ed.). Harlow: Pearson Education.

Fredrickson, B. L. 2013. Love 2.0: Finding happiness and health in moments of connection. New York: Penguin. 
Gardner, R.C. 1985. Social psychology and second language learning: The roles of attitudes and motivation. London: Edward Arnold.

Gardner, R. \& Smythe P. 1975. “Second Language Acquisition: A Social Psychological Approach”. Research Bulletin. University of Western Ontario.

Gustafsson, J.-E., \& Stahl, P.-A. 2005. STREAMS 3.0 user's guide. Mölndal, Sweden: Multivariateware.

Heining-Boynton, A. L., \& Haitema, T. 2007. “A Ten-Year Chronicle of Student Attitudes Toward Foreign Language in the Elementary School”. The Modern Language Journal 91 (2), 149-168.

Henry, A. 2009. “Gender differences in compulsory school pupils’ L2 self-concepts: A longitudinal study”. System, 37(2), 177-193.

Henry, A. 2014. "Swedish students' beliefs about learning English in and outside of school”, in Motivation and Foreign Language Learning: From Theory to Practice, edited by D. Lasagabaster, A. Doiz and J-M Sierra, 93-116. Amsterdam: John Benjamins.

Henry, A. 2015. “The dynamics of possible selves”, in Motivational Dynamics in Language Learning, edited by Z. Dörnyei, P. D. Macintyre, and A. Henry (eds), 83-94. Bristol: Multilingual Matters.

Henry, A., \& Apelgren, B.M. 2008. "Young learners and multilingualism: A study of learner attitudes before and after the introduction of a second foreign language to the curriculum”. System, 36(4), 607-623.

Henry, A., \& Cliffordson, C. 2016. “The Impact of Out-of-School Factors on Motivation to Learn English: Self-discrepancies, Beliefs, and Experiences of Self-authenticity”. Applied Linguistics. 
Henry, A., Korp, H., Sundqvist, P. \& Thorsen, C. (2017, advance access). Motivational strategies and the reframing of English: Activity design and challenges for teachers in contexts of extensive extramural encounters. TESOL Quarterly, doi: 10.1002/tesq.394

Higgins, E.T. 1987. “Self-discrepancy: A theory relating self and affect”. Psychological Review, 94, 319-340.

Hiver, P. 2016. “The triumph over experience: Hope and hardiness in novice L2 teachers”. In Positive Psychology in SLA, edited by P. MacIntyre, T. Gregersen, \& S. Mercer, 168192. Bristol, England: Multilingual Matters.

Hiver, P. (in preparation). “L2 motivation and complex dynamic systems”. In Handbook of L2 Motivation. edited by M. Lamb, K. Csizér, A. Henry \& S. Ryan . Houndmills: Palgrave.

Hiver, P., \& Al-Hoorie, A. 2016. “A dynamic ensemble for second language research: Putting complexity theory into practice”. Modern Language Journal, 100, 1-16. James, W. 1948. Psychology. New York: World. (Original work published 1890).

Keeves, J.P. 1994. “Longitudinal Research Methods”. In The International Encyclopaedia of Education, 2nd ed, vol. 6, edited by T. Husén \& T. Postlethwaite, 3512-3524,. Oxford: Pergammon.

Lamb, M. 2004. “Integrative motivation in a globalizing world”. System, 32, 3-19.

Lamb, M. 2007. “The impact of school on EFL learning motivation: An Indonesian case study”. TESOL Quarterly, 41, 757-780.

MacIntyre, P.D., Baker S., Clément, R., \& Donovan, L. 2002. "Sex and age effects on willingness to communicate, anxiety, perceived competence, and L2 motivation among junior high school French immersion students”. Language Learning, 52, 537- 564. 
MacIntryre, P.D., Dörnyei, Z. \& Henry, A. 2015. “Conclusion: Hot enough to be cool: The promise of dynamic systems research”. In Motivational dynamics in language learning, edited by Z. Dörnyei, P.D. MacIntyre \& A. Henry, 419-429,. Clevedon: Multilingual Matters.

MacIntryre, P.D., Mackinnon, S.P., \& Clément, R. 2009a. “The baby, the bathwater, and the future of language learning motivation research”. In Motivation, Language Identity and the L2 Self , edited by Z. Dörnyei \& E. Ushioda,43-65. Clevedon: Multilingual Matters. MacIntryre, P.D., Mackinnon, S.P., \& Clément, R. 2009b. “Towards the development of a scale to assess possible selves as a source of language learning motivation”. In Motivation, Language Identity and the L2 Self, edited by Z. Dörnyei \& E. Ushioda, 193214. Clevedon: Multilingual Matters.

Mead, G. H. 1934. Mind, self, and society. Chicago: University of Chicago Press.

Markus, H. R., \& Kunda, Z. 1986. ”Stability and malleability of the self-concept”. Journal of Personality and Social Psychology 51, 858-866.

Markus, H.R., \& Nurius, P. 1986. “Possible Selves”. American Psychologist, 41, 954-969.

Muthén, B., Kaplan, D., \& Hollis, M. 1987. “On structural equation modelling with data that are not missing completely at random”. Psychometrica, 52(3), 431-462.

Muthén, L.K., \& Muthén, B.O. 1998-2010. Mplus User’s Guide (6th ed.). Los Angeles: Muthén \& Muthén.

Ortega, L., \& Iberri-Shea. G. 2005. “Longitudinal Research in Second Language Acquisition: Recent Trends and Future Directions”. Annual Review of Applied Linguistics 25 (1), 2645.

Packard; B.W.L \& Conway, P.F. 2006. "Methodological choice and its consequences for possible selves research”. Identity 6 (3), 251-271. 
Phillips, D. \& Filmer-Sankey, C. 1993. Diversification in Modern Languages Teaching: Choice and the National Curriculum. Routledge: London.

Piniel, K, \& Csizér, K. 2015. "Changes in motivation, anxiety and self-efficacy during the course of an academic writing seminar”. In Motivational dynamics in language learning, edited by Z. Dörnyei, P.D. MacIntyre \& A. Henry, 164-194. Clevedon: Multilingual Matters.

Pinner, R. 2016. Reconceptualising authenticity for English as a global language. Bristol: Multilingual Matters.

Ruvolo, A. P., \& Markus, H. R. 1992. "Possible selves and performance: The power of self relevant imagery”. Social Cognition 10 (1), 95-124.

Ryan, S. 2009. “Self and identity in L2 motivation in Japan: The ideal L2 self and Japanese learners of English”. In Motivation, Language Identity and the L2 Self, edited by Z. Dörnyei \& E. Ushioda, 120-143. Clevedon: Multilingual Matters.

Schafer, J. L., \& Graham, J. W. 2002. ”Missing data: Our view of the state of the art”. Psychological Methods, 7(2), 147-177.

Schumann, J. 2015. “Foreword”. In Motivational dynamics in language learning, edited by Z. Dörnyei, P.D. MacIntyre \& A. Henry. Clevedon: Multilingual Matters.

Tachibana, Y., Matsukawa, R. \& Zhong, Q.X. 1996. “Attitudes and motivation for learning English: a cross-national comparison of Japanese and Chinese high school students”. Psychological Reports 79, 691-700.

Taguchi, T., Magid, M., \& Papi, M. 2009. “The L2 Motivational Self System among Japanese, Chinese and Iranian learners of English: A comparative study”. In Motivation, Language Identity and the L2 Self, edited by Z. Dörnyei \& E. Ushioda, 66-97. Clevedon: Multilingual Matters. 
Ushioda, E. 2012. “Motivation: L2 learning as a special case?” In Psychology for language

learning, edited by S. Mercer, S. Ryan \& M. Williams, 58-73. Houndmills: Palgrave

Macmillan.

Ushioda, E. 2013. “Motivation and ELT: Looking ahead to the future”. In International

perspectives on motivation: Language learning and professional challenges, edited by $\mathrm{E}$.

Ushioda, 233-239. Basingstoke: Palgrave Macmillan.

Ushioda, E. \& Dörnyei, Z. 2017. "Beyond global English: Motivation to learn languages in a multicultural world”. Modern Language Journal, 103, xx-xx.

van Dijk, M., Verspoor, M. and Lowie, W. 2011. “Variability and DST”. In A Dynamic

Approach to Second Language Development, edited by M.H. Verspoor, K. de Bot and W.

Lowie, 55-84. Amsterdam: John Benjamins Publishing Company.

Williams, M., Burden, R., \& Lanvers, U. 2002. “„French is the language of love and stuff”:

student perceptions of issues related to motivation in learning a foreign language”.

British Educational research Journal, 28, 503-528.

\begin{abstract}
${ }^{\mathrm{i}}$ McConaughey won the 2014 Academy Award for Best Actor for his role in Dallas Buyers Club. Accessed at: http://www.independent.co.uk/arts-entertainment/films/news/oscars-2014matthew-mcconaughey-best-actor-oscars-2014-acceptance-speech-in-full-9164954.html
\end{abstract}

ii This figure is a projection based on the data reported by Dörnyei and Ryan (2015).

iii It should be noted that in possible selves research substantial use is made of questionnaires. However, these are of a type where participants rate possible and current selves of a generalized nature, and which involve broad psychological dimensions and personality characteristics (Packard \& Conway, 2006). Commonly, instruments invite participants to generate a list of possible selves and, in a second stage, to rate how likely it is that the most personally salient of these possible selves will happen in the future (see e.g. Cross \& Markus, 1991). Questionnaires employing closed-ended Likert scale items of an AMTB-type are hardly ever found (most likely since such instruments could only work for very narrow and specific target domains (Dörnyei \& Ushioda, 2009b)). Because in self-discrepancy research there are neither designs nor techniques for measuring the discrepancies between scores for current and ideal selves generated from closed-ended items, this has likely thwarted the development of an L2-focused instrument more typical of those used by researchers working in a self-discrepancy tradition. 


\section{Appendix One}

Items used in the analyses

\section{EFFORT IN SCHOOL}

EF1 I always look forward to English lessons.

EF2 I devote a lot of time and energy to studying English.

EF3 I focus much more on studying English than any other subject.

EF4 Compared to my classmates I think I study English relatively hard.

\section{CURRENT L2 SELF}

CU1 I see myself as someone who is good at speaking/using English.

CU2 I feel comfortable using English in different situations in my life.

CU3 Communicating in English is not a problem for me.

CU4 I see myself as someone who can speak/use English in many different situations.

CU5 Being someone who can speak/use English is part of the person I am now.

CU6 I feel happy about being a person who can speak English.

\section{IDEAL L2 SELF}

ID1 I see myself as someone in the future who is good at speaking/using English.

ID2 If my dreams come true, I will use English effectively in the future.

ID3 I see myself as someone who in the future uses English in contact with people outside Sweden.

ID4 When I think about the future I can see myself speaking/using English in many different situations.

ID5 Being someone who can speak/use English is part of the person I will be in the future. 